\title{
LA JUSTICIA ESPECIAL PARA LA PAZ: MODELO DE JUSTICIA TRANSICIONAL ACORDE CON LAS ORIENTACIONES Y TENDENCIAS MODERNAS DEL DERECHO Y DE LA JUSTICIA*
}

Carlos Arturo Gómez Pavajeau**

\begin{abstract}
Resumen: El artículo analiza las implicaciones constitucionales de los acuerdos de paz acerca del conflicto armado en Colombia. Para ello, examina normas constitucionales e instrumentos internacionales sobre derechos humanos, confrontando los acuerdos con criterios de justicia en los ámbitos nacional e internacional, para resaltar el papel de la justicia frente a la solución definitiva del conflicto. Mediante la metodología consistente en oponer dicotomías
\end{abstract}

* Este trabajo hace parte de la investigación y libro colectivo, "La Justicia Especial para la Paz. preguntas y respuestas", dirigido y coordinado por el autor y que se publicará en la Defensoría del Pueblo-Dirección Nacional de Defensoría Pública. Para la publicación en la Revista Derecho Penal y Criminología de la Universidad Externado de Colombia, ha sido significativamente ampliado y modificado. Fecha de recepción: 5 de mayo de 2016. Fecha de modificación: 1 de junio de 2016. Fecha de aceptación: 24 de junio de 2016. Para citar el artículo: Gómez PAVAJEAU, CARLos Arturo (2016). "La justicia especial para la paz: Modelo de justicia transicional acorde con las orientaciones y tendencias modernas del Derecho y de la justicia", en Revista Derecho Penal y Criminología, Vol. 38, n. ${ }^{\circ}$ 102, enero-junio de 2016, Bogotá: Universidad Externado de Colombia, pp. 31-68. DOI: http://dx.doi.org/10.18601/01210483.v37n102.03

** Profesor titular de Derecho Penal y Disciplinario de la Universidad Externado de Colombia. Cofundador y Consejero Académico del Instituto Colombiano de Derecho Disciplinario y de la Confederación Internacional de Derecho Disciplinario. Coordinador Académico de Barras de la Defensoría del Pueblo y Consultor de la Escuela Judicial "Rodrigo Lara Bonilla". Bogotá D.C., Colombia. E-mail: gomezpavajeau@hotmail.com. 
para superarlas, revisa las implicaciones de la justicia formal y de la justicia material, estableciendo la superioridad de esta y su relación con la justicia social; analiza las diferencias entre una justicia individual y una justicia global, para demostrar la necesidad de conseguir una justicia integral; contrasta la justicia alternativa a la justicia tradicional, para proponer una justicia integrada; argumenta que la justicia basada en el silogismo formal debe ser superada por una justicia basada en la equidad, para obtener una justicia anclada en la Constitución, con carácter universal y concentrada en los derechos humanos; postula que la justicia soportada en la expiación y en la retribución debe ser superada por una justicia preventiva, reparadora y asegurativa, que permita la construcción de una justicia concentrada en el futuro, sin desconocer el pasado; aclara la justicia con unidad de jurisdicciones y la justicia especial, como componentes de una justicia transicional integrativa; explica la presencia de justicia en distintas entidades que diferencian las funciones o justicia concentrada en una sola entidad, aunque sean distintas funciones, pues es buscada una justicia integradora; expone la búsqueda de una justicia político-constitucional, discutiendo la visión de la justicia como triunfo de la fuerza o la concesión escandalosa de beneficios; exalta que es una justicia en la búsqueda de una discriminación positiva, no de una discriminación negativa, superando la discusión entre justicia para poderosos o justicia para débiles; finalmente, considera que es una justicia, al mismo tiempo, colectiva e individual, lo cual es mucho más completo que una justicia parametrizada o una justicia individualizada.

Palabras clave: Paz; Justicia; Justicia transicional; Justicia Especial para la Paz; Acuerdos de paz; Constitución.

\title{
SPECIAL JUSTICE FOR PEACE: A TRANSITIONAL JUSTICE MODEL ACCORDING TO MODERN TENDENCIES AND ORIENTATIONS OF LAW AND JUSTICE
}

\begin{abstract}
The article analyses the constitutional implications of the peace agreement about Colombia's armed conflict. It examines constitutional rules and international instruments about human rights, confronting the agreement with justice criteria in the national and international context, to underline the role of justice for the definitive solution of the conflict. By using the methodology of opposing concepts, it reviews the implications of formal justice and material justice, to establish the superiority of the last one and it's relation with social justice; it analyses the differences between individual justice and global justice, to demonstrate the need to obtain an integral justice; it contrasts alternative justice and traditional justice, to propose an integrated justice; it explains that justice based upon the formal syllogism should be overcome by a justice based upon equity, to obtain a justice anchored in the
\end{abstract}


Constitution, universal and concentrated in the human rights; it hypothesizes that justice supported in the atonement and retribution should be overcome by a justice that is preventive and restorative, that allows the construction of a justice focused in the future, without ignoring the past; it clarifies that justice with one jurisdiction and special justice are the components of a integrative transitional justice; it explains the presence of justice in different institutions with different functions and justice concentrated in one institution, although with different functions, because there is a search for an integrative justice; it exposes the search for a constitutional and political justice, discussing the vision of justice as a triumph of the force or the scandalous concession of benefits; it exalts that it is a justice in search of a positive discrimination, not a negative discrimination, overcoming the discussion between justice for the powerful and justice for the weak; finally, it considers that it is a justice both collective and individual, which is more complete than a justice based on parameters or an individual justice.

Keywords: Peace; Justice; Transitional Justice; Special Justice for the Peace; Peace Agreement, Constitution.

\section{INTRODUCCIÓN}

El conflicto político-social colombiano es quizás uno, si no el más, de los más antiguos, persistentes, sistemáticos, crueles, deshumanizados y generalizados del globo terráqueo, con implicaciones internacionales en el ámbito latinoamericano -no desdeñando el universal-, lesionando no solo el in se de la organización política y jurídica de nuestro país - unidad de la nación, aseguramiento de la vida, la convivencia, el trabajo, la justicia, la igualdad, el conocimiento, la libertad y la paz, dentro de "un marco jurídico, democrático y participativo que garantice un orden político, económico y social justo" (preámbulo Carta Política, parte primera)-, sino también los propósitos de integración regional, en tanto afecta el compromiso de "impulsar la integración de la comunidad latinoamericana" (preámbulo Carta Política, parte segunda, y artículo 9, especialmente lo indicado en su inciso 2), todo lo cual no solo afecta de manera global y sistemática los principios fundamentales del Estado (artículos 1 a 10), sino también a toda la parte filosófica (artículos 11 a 95) e incluso a la orgánica (artículos 96 y siguientes), especialmente, cuando contempla principios, valores y derechos constitucionales.

Se trata de un conflicto que temporalmente ya no es de años, tampoco de lustros. Se perfila con tendencia de siglos, hasta el punto de que muchas de las generaciones nacidas a partir de mediados del siglo Xx no conocen la paz; se han formado en la indiferencia y tolerancia ante el conflicto, en una especie de "sálvese quien pueda" y "mientras a mí no me toque, las cosas se pueden aguantar". Tan profundas son sus huellas sociológicas y psicológicas que asistimos a una pérdida de principios como 
los de humanidad, solidaridad y capacidad de asombro ante las violaciones a los derechos de los demás ${ }^{1}$.

Tal realidad indiscutible, pero no inexorable, contradice la esencia misma del sentimiento de justicia internacional y nacional, quebrantando no solo la dignidad de las personas y sus derechos nucleicos inherentes y esenciales, sino también globalmente la dignidad de sus culturas (artículos 1 y 70, numeral 2), amén de los principios inspiradores de la Carta Universal de Derechos Humanos y la Carta Interamericana de Derechos y Deberes del Ciudadano, así como sus instrumentos convencionales representados en el Pacto Internacional de Derechos Civiles y Políticos, Pacto Internacional de Derechos Económicos, Sociales y Culturales y, de la segunda, la Convención Americana sobre Derechos Humanos.

Ha llegado la hora, sin justificación de ninguna clase, de poner fin a tan ignominiosa situación social e individual de sus habitantes. La justicia no puede encarnizarse omisivamente viendo cómo se continúa afectando a la población más débil física, económica y socialmente, en perjuicio del artículo 13 de la Carta Política, pero igualmente debe transformar paulatinamente, en dialéctica de equilibrio, su enfoque de la justicia formal hacia la material, un concepto filosófico de derecho estructural hacia el funcional, una concepción de normas prohibitivas y de sanciones negativas hacia una de normas de estímulo y sanciones positivas como inteligencia de sus instituciones jurídicas y, finalmente, el paso de las sanciones expiatorias o meramente retributivas y ejemplarizantes hacia medidas alternativas orientadas por una Política Criminal coherente y respetuosa del orden constitucional y del Orden Público Internacional de los Derechos Humanos (artículos 4 y 93, ibídem), que mire hacia el futuro en términos globales y no insularmente individuales, sin desconocer el pasado y futuro de las víctimas.

Los acuerdos de paz de La Habana entre el Gobierno Nacional y las FARC, especialmente en lo que tiene que ver con la llamada "Justicia Especial para la Paz", presenta novedades que se traducirán no solo en prácticas sociales e individuales, institucionales y políticas, sino también académicas y con profundas repercusiones en el estudio y enseñanza del Derecho en Colombia.

1 Un estudio de neurosicología realizado en Colombia demuestra, a partir de resultados que apuntan a que en nuestro país solo un $19 \%$ de los adultos reconocen rostros humanos con miedo y un $27 \%$ de tristeza, una baja empatía que sugiere cuáles serían las causas del conflicto o sus consecuencias. El estudio de campo a partir de una muestra significativamente grande y amplia fue llevado a cabo por el Instituto de Envejecimiento de la Universidad Javeriana y el Centro de Memoria y Cognición del Hospital Universitario de San Ignacio. Fue objeto de análisis por la científica Diana MatallanA en una conferencia dictada en Armenia, en el marco del LIV Congreso Colombiano de Psiquiatría, cuyo título es "La cognición social en la Encuesta Nacional de Salud Mental de 2015: lecciones aprendidas desde las neurociencias sociales en escenarios del posconflicto y conflicto colombianos" (Nota del periodista JuAn CAMILO Maldonado Tovar, "Colombianos, ¿programados para ser indolentes?” en El Espectador, n. 37.214 , lunes 13 de junio de 2016, pp. 22 y 23). 
Independientemente del juicio y pronóstico sobre si la misma se hará o no realidad, y sobre todo si los concernidos en el conflicto tienen o no la voluntad de superar el "estado de cosas" existente, afloran criterios, conceptos, directrices, orientaciones, nuevas visiones y tendencias que permearán la práctica jurídica y transformarán la formación de los nuevos juristas posconflicto, impactando de manera positiva el entendimiento de nuestro orden jurídico y social, en pos de una "justicia social” como se enarbola por el Preámbulo de la Carta Política.

En un escrito anterior, titulado “¿Justicia sin reglas?: formalidad vs. materialidad”, publicado en una investigación colectiva de la Defensoría del Pueblo (GómEz PAVAJEAU, 2015, pp. 17 a 24), hacíamos algunas consideraciones que hoy queremos reafirmar y ampliar, toda vez que dichas reflexiones tenían como marco la Ley 975 de 2005 , en la cual ya se avistaba un concierto de nuevos y complementarios principios de justicia que hoy, ante los acuerdos de paz de La Habana, parecen consolidarse.

La Barra Académica de la Dirección de Defensoría Pública que se encarga de la defensa pública de los "postulados" en el marco de la ley citada, abre nuevamente los horizontes de discusión, planteando preguntas claves y cruciales, con sus respectivas respuestas aproximativas, para el entendimiento y rendimiento jurídico de los acuerdos de La Habana, con la convicción y vocación de contribuir cada uno con su grano de arena para el buen suceso que hoy se vislumbra como una luz al final del túnel, de lo cual nadie absolutamente puede estar exento, mucho menos la academia y aquellos que conocen por más tiempo, rigor y profundidad la justicia transicional.

La disertación que a continuación se presenta no es voz oficial ni de la Defensoría del Pueblo ni de la Barra Académica, institución que dirijo y coordino. Sin más ni más, es una reflexión producto del estudio y ejercicio del Derecho por más de treinta y cinco años, en lo práctico y en lo teórico, así como en lo oficial y en lo académico. Es mi visión particular, correcta o equivocada, pero constitutiva de ese grano de arena que nadie puede dejar de aportar en estos momentos decisivos de nuestra colombianidad, con lo cual cumplo, desde la academia que es mi verdadera y genuina vocación, con el mandato del artículo 22 de la Carta Política, según el cual "la paz es un derecho y un deber de obligatorio cumplimiento", demandables y exigibles a todos, puesto que el ejercicio de los derechos implica responsabilidades, entre las cuales, por supuesto de conformidad con el artículo 95 ibídem, se encuentra cumplir con los deberes constitucionales (inciso 1), especialmente con el de respetar los derechos ajenos y no abusar de los propios (numeral 1), obrar conforme al principio de la solidaridad social (numeral 2), respetar y apoyar a las autoridades legítimamente constituidas (numeral 3), defender y difundir los Derechos Humanos como fundamento de la convivencia pacífica (numeral 4), participar en la vida política, cívica y comunitaria del país (numeral 5), propender al logro y mantenimiento de la paz (numeral 6), y colaborar para el buen funcionamiento de la administración de justicia (numeral 7). 
A continuación, señalo lo que se podría constituir, desde el punto de vista académico y de la enseñanza del Derecho que se avizora revisar hacia el futuro, en el Decálogo de una justicia "justa". No otra cosa pueden significar las aspiraciones de la Justicia Transicional encarnada en la Justicia Especial para la Paz de los acuerdos de La Habana.

Ha llegado la hora de aplicar el espíritu original, genuino y verdadero de la Carta Política: solo existe justicia cuando las oportunidades políticas, sociales, económicas y jurídicas permiten un equilibrio entre lo antropocéntrico y lo sociocéntrico, aunque privilegiando a lo primero cuando no haya posibilidad cierta de lograrlo, lo cual pasa por reconocer y practicar que la justicia involucra ejercicio y respeto de derechos, pero también de deberes. Tanto unos como otros hacen parte de los principios del Estado colombiano (artículos 1 y 2) y de la Parte Dogmática de la Carta Política (artículos 11 a 94: Derechos, especialmente) y 95 (Deberes, especialmente), de manera que su carácter de justiciables no puede ponerse en duda: lo escrito teóricamente hay que escribirlo e inscribirlo en la praxis de una verdadera justicia.

\section{JUSTICIA FORMAL Y JUSTICIA MATERIAL: HACIA UN CONCEPTO DE JUSTICIA SOCIAL}

Iusnaturalismo y positivismo, a través de discusiones que trascienden milenios, aportando lo bueno y desechando lo negativo, han permitido decantar la idea según la cual la ley no es igual, o por lo menos es imposible una sinonimia, a la Justicia y al Derecho.

La equiparación burda y cuadriculada entre ambos conceptos conllevó, recientemente, a la experiencia "injurídica" del nacionalsocialismo alemán de HITLER, cuyos recuerdos querrían ser borrados desde el punto de vista psicológico-individual, pero no desde el psicológico-social, pues si no se conoce la historia existe la posibilidad de repetirla.

El positivismo crudo, desnudo e irracional, que llevó a sus extremos el aforismo romano según el cual "la ley es dura pero es la ley", fue la ocupación práctica del Derecho en dicha época, razón por la cual la tarea inmediata de la reconstrucción del sentimiento jurídico perdido luego de finalizada la Segunda Guerra Mundial fue separar tales conceptos, lo que se encomendó al llamado constitucionalismo moderno ${ }^{2}$.

Nuestra Carta Política así lo ha establecido, aunque no explícitamente, pero muy a pesar de que en el inciso 1 de su artículo 230 señala que "los jueces, en sus providencias, solo están sometidos al imperio de la ley”, el artículo 4, que hace parte

2 Así, de una manera clara y evidente, el numeral 3 del artículo 20 de la Ley Fundamental de la República Federal de Alemania. 
de los principios rectores constitucionales y de la Parte Dogmática de la misma, manda que la Constitución es norma de normas, que por demás, según el artículo 2, las autoridades públicas tienen como fin principal "garantizar la efectividad de los principios, derechos y deberes consagrados en la Constitución", los derechos constitucionales son fuente del derecho de aplicación inmediata (artículo 85). Por tanto, la ley se encuentra sometida al Derecho (artículos 6 y 95) y prima sobre ella el Bloque de Constitucionalidad (artículo 93).

La Parte Dogmática, en cierta forma, condiciona la interpretación de la Parte Orgánica $^{3}$. También en esta se encuentran principios, valores y derechos constitucionales al rechazarse el criterio a rúbrica para determinarlos ${ }^{4}$, y la fuerza vinculante de la primera hace que incluso una reforma constitucional sobre ella pueda considerarse como inconstitucional, pues ya no se trataría de una reforma sino de una sustitución de la constitución ${ }^{5}$. En fin, también el Preámbulo tiene valor jurídico condicionante de la validez del orden jurídico ${ }^{6}$.

El positivismo jurídico allí flaquea, se fortalece en ius naturalismo crítico o un positivismo valorativo en nuestra Carta Política, que termina de acuñarse cuando establece valores superiores en su artículo 1 y, muy especialmente, derechos constitucionales no positivizados en su artículo 94.

Las formas ceden el paso, sin que desaparezcan, a los aspectos sustanciales de la justicia, lo que viene definido de manera explícita por el artículo 228, según el cual en la función de la Administración de Justicia "prevalecerá el derecho sustancial".

No en vano, pues, la jurisprudencia constitucional ha dicho sobre la "justicia material":

Pero toda interpretación, incluso la de más valía como es la sistemática, debe orientarse y conducirse de conformidad con los principios. "Los principios juegan un papel esencial en la interpretación jurídica, en especial cuando se presentan casos difíciles, producto del conflicto de varias normas"?

3 Corte Constitucional, Sentencias C-178 de 1995, C-836 de 2001 y T-116 de 2004.

4 Ídem., Sentencias T-02 de 1992 y T-532 de 1992.

5 Gómez Pavajeau (2015, pp. 17 a 24); Corte Constitucional, Sentencias C-551 de 2003, C-970 de 2004, C-971 de 2004, C-1040 de 2005, C-588 de 2009, C-141 de 2010, C-303 de 2010, C-288 de 2012, C-579 de 2013, C-577 de 2014, C-150 de 2015 y C-053 de 2016.

6 Ídem., Sentencias C-479 de 1992, C-067 de 2003, C-477 de 2005 y C-544 de 2010

7 Ídem., Sentencia T-058 de 1995. 
Cuando las normas legales "son claras, razonables y eficaces para la obtención de su derecho", la consecuencia es que "la apelación a los principios no es conducente" 8 .

El ideal de justicia material es "consustancial al Estado Social de Derecho que emerge de los principios, valores y derechos constitucionales" ${ }^{\text {. El prin- }}$ cipio de justicia material ha sido calificado como "un valor superior del orden constitucional" 10 y, por tanto, es deber del juez "hacer efectivo el principio de justicia material" 11 , lo que impone la idea según la cual "el juez del Estado Social de Derecho debe optar necesariamente por satisfacer las exigencias concretas de la justicia material" ${ }^{12}$.

Es posible que el principio de justicia material "entre en conflicto con otros principios como el de certeza, seguridad y objetividad jurídica, caso en el cual, si no se tratare de normas prohibitivas o de mandato, la ponderación jurídica impone su prevalencia; puesto que "el principio de justicia material podría prevalecer sobre cualquier consideración legal" ${ }^{13}$ y sobre criterios formales ${ }^{14}$.

"La búsqueda de un ideal de justicia material consagrado en la Carta, no puede confundirse con la posibilidad de que cada uno reclame la concreción de ese propósito desde su particular perspectiva y según su concepción de lo justo"15.

"El principio de la prevalencia de la justicia material no puede traducirse en una eliminación de todas aquellas reglas que aplicadas de manera clara y específica a un caso concreto no producen el fin propuesto desde el punto de vista del sujeto afectado. Existe un ámbito de imponderables personales que pueden ser determinantes en el resultado que el derecho produzca en los individuos y que no pueden ser previstos por las normas jurídicas" 16 .

Contundentemente, se dice por la doctrina que "el derecho material determina el programa que debe ser desarrollado en el proceso" y la "responsabilidad por la solución justa de los casos particulares se traslada progresivamente de la ley al tribunal" (VOLK, 2001).

8 Ídem., Sentencia T-058 de 1995.

9 Ídem., sentencias T- 53 de 1994 y T-084 de 1998.

10 Ídem., Sentencia C-004 de 2003.

11 Ídem., Sentencia C-199 de 2002.

12 Ídem., Sentencia T-597 de 1992.

13 Ídem., Sentencia T-058 de 1995.

14 Ídem., Sentencia T-339 de 1997.

15 Ídem., Sentencia C-651 de 1997.

16 Ídem., Sentencia T-058 de 1995. 
La jurisprudencia constitucional no se queda atrás y precisa que "los principios expresan normas para el presente" y, por sí mismos, "los principios son normas que establecen un deber ser específico del cual se deriva un espacio de discrecionalidad legal y judicial" 17 .

El Estado Social comporta una "pérdida de la importancia sacramental del texto legal entendido como emanación de la voluntad popular y mayor preocupación por la justicia material y por el logro de soluciones que consulten la especificidad de los hechos", dice la jurisprudencia constitucional. Agrega que la pretensión racionalista de prever todos los conflictos y asignarles jurídicamente por la norma una solución es algo infructuoso, requiriéndose, por tanto, un juez que sirva "para mejorar las condiciones de comunicación entre el derecho y la sociedad”, desplazándose la importancia de la validez formal y material, contenidas pretendidamente en la ley, hacia la decisión judicial en tanto compromiso con "la defensa de los contenidos materiales" 18 .

En fin, la justicia formal debe complementarse y corregirse a través de la justicia material, visión que se impone a toda autoridad pública, ya sea legislativa, ejecutiva o judicial, debiendo todo el aparato o andamiaje público centrarse en su consecución, materializando así la búsqueda teleológica y valorativa -sin desdeñar de la lógica formal, pero subordinándola cuando sea necesario- de la "justicia social", tal cual lo ordena el Preámbulo constitucional.

El "Acuerdo sobre las víctimas del conflicto" encarna una visión de justicia material en tendencia a la justicia social, puesto que en el tema delictual no pone el acento en el victimario y el quebrantamiento de la ley, sino que demanda necesariamente la atención sobre "1. Derechos humanos de las víctimas y 2 . Verdad, tratando de dar contenidos que satisfagan las reivindicaciones de quienes han sido afectados por la larga confrontación".

Entiende que ello no se puede llevar a cabo a través de simples fórmulas jurídicas, se requiere, necesariamente, asumir una "Declaración de principios" fundados en: 1) el reconocimiento de las víctimas -ciudadanos con derechos-; 2) el reconocimiento de responsabilidad sin intercambio de impunidades; 3) satisfacción de los derechos de las víctimas de la mejor manera en el marco del fin del conflicto; 4) la participación de las víctimas en la solución del conflicto; 5) el esclarecimiento de la verdad, lo que involucra las múltiples causas del conflicto, sus orígenes y sus efectos, tanto a nivel individual como general de las víctimas y la sociedad; 6) la reparación efectiva de las víctimas; 7) su protección y seguridad; 8) las garantías de no repetición; 9)

17 Corte Constitucional, Sentencia T-406 de junio 5 de 1992, M.P. Ciro ANGARITA BARón, en Gaceta Constitucional Tomo 2, junio de 1992, p. 199.

18 La misma sentencia, ídem, pp. 196 y 197. 
la consecución de la reconciliación individual y social; 10) el enfoque de derechos, dentro del marco de su inherencia al ser humano, universalidad, igualdad, indivisibilidad, interdependencia, globalidad, justicia, equidad y progresividad, tanto los de carácter individual como social, económicos y culturales, 11) con la correlativa exigencia de deberes constitucionales; y 12) con la implicancia de que derechos y deberes son justiciables en un ámbito de integralidad.

Tales declaraciones de principios nos ubican en materia de interpretación de normas y asignación de efectos jurídicos más allá de los límites simplemente formales, toda vez que se reconoce que esa "Declaración de principios" sirve de brújula para "asegurar que la satisfacción integral de sus derechos -víctimas- a la verdad, la justicia, la reparación y la no repetición, esté en el centro del acuerdo". Al efecto se contempla un aparte 5.1.2. Justicia, que da cuenta de la Jurisdicción Especial para la Paz, por el que se abordan en su desagregado I los llamados "Principios básicos del componente de Justicia Integral de Verdad, Justicia, Reparación y No Repetición (SIVJRNR)"19.

El tránsito de la justicia formal a la material, y especialmente en términos de equidad, se facilita con el mandato de implementar juicios basados en la perspectiva de género, en búsqueda de la plena verdad sobre lo ocurrido, lo cual marca diferencias con una justicia tradicional que en gran medida se conforma con verdades procesales. Allí se introduce la idea de que el Sistema Integral "tiene un enfoque diferencial y de género" (puntos 5.1. y 5.1.2. desagregado I-Principios básicos-, numerales 7 y 8).

\section{JUSTICIA INDIVIDUAL Y JUSTICIA GLOBAL: HACIA UN CONCEPTO DE JUSTICIA INTEGRAL}

La justicia, en principio, debe hacerse caso por caso, razón por la cual el sistema de justicia procesa el conflicto social a través de la determinación e individualización modal, temporal y espacial de un hecho, mirado como un episodio individual, perdiendo nociones generales y globales determinantes y vinculantes dentro del sistema político, social, económico y jurídico.

Tal cual lo que sucede al interior del sistema de justicia, empero, si se quiere obtener la paz y la convivencia, la idea de justicia debe trascender de lo individual a lo global, ya no es asunto de juicio histórico-episódico, sino general, del cual deben ocuparse medidas judiciales y no judiciales, en todos y absolutamente todos los ámbitos de la vida nacional.

Por ello se establece que "todos los operadores del componente de justicia del SIVJRNR deberán interpretar las normas pertinentes y tomar sus decisiones teniendo

19 Para el efecto de la Interpretación por Principios ver Gómez PAVAJEAU (2012, pp. 55 y ss.). 
como principio orientador la paz, como derecho síntesis, es condición necesaria para el ejercicio y disfrute de todos los demás derechos" (punto 5.1.2. desagregado III -Procedimiento, órganos y sanciones-, numeral 75).

Legislativo, ejecutivo y judicial deben alinearse sincrónicamente en hacer de lo justo algo más complejo que lo individual-episódico, pues el conflicto va más allá de las partes directamente concernidas, trasciende a la familia, sociedad, Estado y hasta involucra a la comunidad internacional.

En fin, como dice BARCELlONA, "es necesario, pues, reconducir las abstractas categorías dogmáticas, las concepciones de la ciencia jurídica, a aquellas relaciones histórico-materiales que las han originado", esto es, "se debe transformar al jurista teórico en un jurista capaz de incidir sobre la realidad" y, como tal, no puede perder el contacto con ella (BARCELlona, Hart y MüCKEnBERger, 1993, pp. 16, 24 y 29).

Se implementan así mecanismos de integralidad, con componentes judiciales y no judiciales para dar cumplimiento a 1) un Sistema Integral de Verdad, Justicia, Reparación y No Repetición; y 2) compromiso con la promoción, el respeto y la garantía de los Derechos Humanos.

Se instituyen así mecanismos de justicia "sustancial o material"20 como la Jurisdicción Especial para la Paz con medidas específicas de reparación (puntos 5.1.2. (puntos 5.1. y 5.1.2. desagregado I -Principios básicos-, numerales 4 y 9) y no jurisdiccional como la Comisión para el Esclarecimiento de la Verdad, la Convivencia y la No Repetición (punto 5.1.1.1.); la Unidad Especial para la Búsqueda de Personas dadas por Desaparecidas en el contexto y en razón del conflicto (punto 5.1.1.2), tal como se proclama en la introducción de los principios y en el punto 5.1.

Si bien la Comisión para el Esclarecimiento de la Verdad, la Convivencia y la No Repetición juega un papel determinante en la búsqueda de tales valores, se fijan claramente sus criterios orientadores y competencias, en el sentido de que "sus actividades no tendrán carácter judicial, ni podrán implicar la imputación penal de quienes comparezcan ante ella. La información que reciba o produzca la Comisión no podrá ser trasladada por esta a autoridades judiciales para ser utilizada con el fin de atribuir responsabilidades en procesos judiciales o para tener valor probatorio; ni las autoridades judiciales podrán requerírsela" (punto 5.1.1.1.), sin que ello sea óbice para dejar de lado las responsabilidades de tipo colectivo a cargo del Estado, los rebeldes, los paramilitares o cualquier otro grupo al margen de la ley.

Sabiamente, al final del punto, se consagra un principio según el cual "ningún mecanismo del Sistema primará sobre el otro. Cada mecanismo deberá cumplir su

20 Para el efecto, Gómez Pavajeau (2009). 
función principal de la manera más ágil posible y sin duplicar aquellas de los otros mecanismos, para lo cual se establecerán los protocolos de colaboración necesarios".

En general, se persigue develar "los orígenes y las múltiples causas del conflicto, los principales factores y condiciones que han facilitado o contribuido a la persistencia del conflicto y los efectos e impactos más notorios del conflicto sobre la población". Es así como se dice que "la integralidad del Sistema contribuye a sentar las bases para la recuperación de la confianza, para la convivencia en un escenario de construcción de paz, y para una verdadera reconciliación entre todos y todas los colombianos y colombianas" (punto 5.1.) y la no repetición contribuye a "reversar los efectos del conflicto y a cambiar las condiciones que han facilitado la persistencia de la violencia en el territorio", garantizando incluso los derechos económicos, sociales, culturales y ambientales (punto 5.1.4.).

La participación de víctimas en foros organizados por la cooperación internacional y academia colombiana, así como la llevada a cabo en las mesas de La Habana, facilitan el contacto de los titulares de derechos con los mecanismos de justiciabilidad, cumpliendo en cierta forma con la "participación de todos en las decisiones que los afectan”, según lo establece el artículo 2 de la Carta Política. No en vano, pues, se dice que "el éxito del Sistema Integral depende también de que encuentre la más amplia aceptación en la sociedad" (punto 5.1.).

Trabajos y actividades individuales y colectivas frente a víctimas individuales y colectivas son de la esencia de las medidas reparadoras (parte I. Sanciones aplicables del listado de sanciones). El aparte 5.1.3.3. Ibídem da cuenta de la "Reparación colectiva en el fin del conflicto", el 5.1.3.4. de la "Rehabilitación psico-social"; el 5.1.3.5. de los "Procesos colectivos de retornos de personas en situación de desplazamiento y reparación de víctimas en el exterior"; el 5.1.3.6. se refiere a "Medidas sobre restitución de tierras"; el 5.1.3.7. sobre "Adecuación y fortalecimiento" de la política de atención y reparación de víctimas con las "Garantías de no repetición" (punto 5.1.4.) y el "Compromiso con la promoción, el respeto y la garantía de los derechos humanos" (punto 5.2.).

El punto 5.1.3 consagra medidas globales e individuales de reparación mediante actos colectivos formales, públicos y solemnes, con el fin, según 5.1.3.1., de "contribuir a la satisfacción de los derechos de las víctimas, marcar el momento simbólico de un nuevo comienzo, y crear un ambiente favorable para la construcción de la paz, en el marco del fin del conflicto".

El que la paz debe ser estable y duradera es un cometido fundamental y central (punto 5.1.2. desagregado I -Principios básicos-, numerales 2 y 6). Ella presupone que "la comunidad política no es solo una unión de coetáneos, sino también un vínculo entre generaciones que se eslabonan en el tiempo. La justicia es prospectiva en cuanto considera que una época influye ineluctablemente sobre las posteriores. 
Se trata de una justicia prospectiva respetuosa de los valores del presente y a la vez preocupada por acabar con conflictos que no deben ser perpetuados, en aras de la defensa de los derechos de las futuras generaciones", para lo cual debe apreciarse y "evaluar la complejidad, duración y gravedad del conflicto armado interno con el fin de diseñar y adoptar los mecanismos de justicia para lograr la paz dentro del respeto a los parámetros establecidos en el derecho internacional, en especial la garantía de los derechos humanos" (punto 5.1.2. desagregado I-Principios básicos-, numerales 3 y 5 ).

Se prevé además participación individual y colectiva en los procesos judiciales y las decisiones procurarán inscribir los hechos y conductas determinadas en el "contexto del conflicto armado" (punto 5.1.2. desagregado III -Procedimiento, órganos y sanciones-, numerales 46 literal (e), 48 literal (i) y 54 literal (d).

Corolario de los efectos más allá de los interpartes e interpares, con trascendencia a lo social, imponen la "rendición de cuentas sobre violaciones a los derechos humanos e infracciones al DIH ocurridas a lo largo del conflicto" (puntos 5.1. y 5.1.4.).

Con toda razón, evidentemente, "el éxito del sistema integral depende, también de que se encuentre la más amplia aceptación en la sociedad” (punto 5.1.).

\section{JUSTICIA TRADICIONAL Y JUSTICIA ALTERNATIVA: HACIA UN CONCEPTO DE JUSTICIA INTEGRADA ${ }^{21}$}

La justicia tradicional se expresa, en principio, en la organización de justicia adoptada para tiempos de normalidad, aquella que tiene vocación de permanencia. No obstante, la misma se ve desbordada por la necesidad de institucionalizar en el sistema aspectos alternativos no conocidos en ella, como sucede con institutos como la conciliación o el principio de oportunidad en sus versiones amplia y concreta, fundados en la idea de instrumentos procesales dispositivos. Tales figuras involucran, más que una definición de lo justo o injusto a partir de referentes legales, la operatividad de criterios político-criminales que permitan salidas alternativas a las tradicionales de prisión intramural y recorte de derechos.

Más allá de un concepto formal-normativo, instituido a partir de la letra de la ley, se requieren nuevos elementos político-criminales que superen lo individual-episódico y trasciendan hacia lo sustancial global, pues todo conflicto tiene raíces que no se alcanzan a divisar y apreciar. Por lo tanto, resultan imposibles de valorar, si no avanza-

21 Parte de este desarrollo fue tomado, en lo sustancial de la teoría jurídica, de mi libro Crítica disciplinaria (2016). 
mos hacia una visión integral del conflicto, de manera que se hace imperioso integrar justicia tradicional y justicia alternativa en la consecución de una justicia integrada.

Ello puede hacerse con vocación de permanencia, sistematicidad y simultaneidad, tal cual ocurre con la integración de las medidas alternativas de justicia a la justicia institucionalizada de manera permanente. Pero también, con vocación de temporalidad, especialidad y simultaneidad, como la justicia transicional que se plantea en la "Justicia Especial para la Paz".

Un concepto de justicia integrada no debe perder de vista las funciones social y promocional del derecho, ni la postulación de las ideas de norma y sanción positivas ${ }^{22}$.

En dicha conceptualización, cumple un papel significativo el Estado social, toda vez que, por su característica fundamental de incidir en la realidad social, económica y política, sirve de catalizador para la creación de un clima propicio y favorable para el desenvolvimiento del talento humano, cuyo reconocimiento se hace estimulando el buen hacer y sancionando positivamente su cumplimiento, a través de la creación de espacios y oportunidades siempre necesarias para rectificar el camino, a veces equivocado, por el que ha optado el libre desarrollo de la personalidad.

El Estado Liberal utiliza en mayor medida, sin que ello sea exclusivo y excluyente, técnicas jurídicas diferenciales con aquellas que aparecen como prototípicas del Estado social, muy a pesar de que, en la lógica kelseniana, tradicionalmente "las técnicas de desalentamiento han sido consideradas como más eficaces y genuinas técnicas de control social” (LARA CHOGOYÁ, 2005, p. 554).

Esto es, se identifican técnicas jurídicas de desalentamiento en la órbita de los ordenamientos jurídicos del Estado liberal clásico y, por otro lado, técnicas de alentamiento con el Estado social. Las primeras se expresan "a través de la emisión de mandatos negativos (prohibiciones)", con sus correspondientes, en caso de infracción de la norma, sanciones negativas; no obstante, KELSEN visionó que estas no resultaban incompatibles con su sistema jurídico, pues eventualmente también tendría cabida la sanción positiva (ídem, pp. 555 y 557).

Por tales razones, y como hemos expresado en otra oportunidad (GómEZ PAVAJEAU, 2009), para lograr sus cometidos el Estado utiliza los mecanismos tradicionales y también los modernos de la sanción jurídica, entendida esta como la adjudicación de efectos de tal índole a un comportamiento, en su más acabado sentido de sanción o premio (artículo 6 del Código Civil). 
Esta última es característica definitoria de la noción de Estado social, según anota Bоввіо, para efecto de ir mucho más allá de las meras sanciones represivas, para dar cabida a las sanciones estímulos (BOBBIO, 1990, pp. 371 y ss.), que, como tal, también deben cumplir una destacada labor en la función de direccionamiento de conductas.

El sistema sancionatorio del Estado es complejo y se encuentra multiformado, dependiendo cada especie de la funcionalidad que cumple, por lo que el cometido es precisar, describiendo, pero esencialmente valorando, lo que le corresponde por la forma y el contenido a una Justicia integrada. Por ello se dice, con gran acierto, que "asume la noción de control social como comprehensiva de las muy diversas formas de conducir la conducta humana" (MONTOYA BRAND, s.f.).

La regulación social aparece como una nueva forma de estrategia en la intervención del Estado, lo cual demanda un cambio de paradigma en la concepción jurídica de las instituciones, habida cuenta que la nueva evolución jurídica, impondrá la idea de consecución de "resultados prácticos" y "objetivos materiales", instaurándose la idea de un Derecho orientado por fines políticos en el cometido institucional (CALVO GARCÍA, 2005, pp. 28, 32 y 48).

Boввio destaca cómo en la Teoría del Derecho se produce un giro que va de las preocupaciones exclusivas y excluyentes por lo estructural hacia una enfatización en lo funcional, lo que implica que el acento se traslade del punto de vista jurídico al sociológico. Es la consecuencia del paso del Estado liberal al Estado social, toda vez que ya "la función del Derecho no es solamente la de mantener el orden constituido, sino también la de cambiarlo adaptándolo a los cambios sociales" (BOBBIO, op. cit., pp. 256, 257 y 264).

Las ideas estructuralistas de lo jurídico, propias del Estado liberal de Derecho, se permean de finalidad -funcionalidad-en el modelo que resulta matizado por el concepto de Estado social y, en consecuencia, como dice FARALLI, "el derecho no es un sistema cerrado e independiente: este es, respecto del sistema social considerado en su conjunto, un subsistema que se encuentra al lado, y en parte se superpone y en parte se contrapone, a otros subsistemas (económico, cultural, político)" (FARALLI, 2007 pp. 23 y 24). La función social implica una lógica del medio-fin en la cual el Derecho es un instrumento de gobierno, pero el punto de vista social no puede anular el individual, de allí que su verdadera función "es la de realizar la justicia como modo específico de superar la inseguridad colectiva” (BовBIO, op. cit., pp. 272 y 273).

La búsqueda de la eficacia aparece como un cometido prioritario en la tarea del Estado, lo cual ha sido un aporte de la sociología jurídica norteamericana, de allí que el "derecho útil" tenga su medida en el "logro de objetivos o consecución de funciones". Esto es, si se añade la eficiencia, los logros deben conseguirse con un uso eficiente y racional de los recursos estatales. Se impone así la penetración de la lógica del sistema político en el sistema jurídico, lo cual implica orientar la tarea de 
la aplicación del Derecho más por la vía de la "realización de funciones", lo cual es propio del Estado social, que por la del "seguimiento de reglas", ámbito natural del Estado liberal (CAlvo García, op. cit., pp. 76, 77 y 103).

El Estado actual, ante los desafíos que las nuevas realidades ofrecen, reacciona con "un modelo de control de dimensiones extraordinariamente complejas", afirma Calvo García. Las relaciones jurídicas no se entienden sobre la base de limitaciones a la actividad estatal, sino también como "acción social positiva directa", todo lo cual conlleva a que "las normas prohibitivas reforzadas mediante sanciones negativas ya no son el único instrumento de este tipo de derecho; al contrario, surgen nuevos medios y formas de control positivo que promueven un cambio sustancial en la fisonomía del derecho" (resaltado fuera de texto) (ídem, pp. 28, 31 y 107).

Esa nueva fisonomía está dada por la necesidad de adoptar mecanismos de "control positivo y negativo más amplios y sofisticados" (ídem, pp. 104 y 105). BoBBIO (op. cit., p. 268) precisa cómo en el Estado social "la función primaria de regular los comportamientos ha asumido formas distintas a la tradicional, que reposaba exclusivamente en la intimidación a través de la sanción negativa", de tal manera que ahora el Derecho desarrolla "también una función de estímulo, de promoción, de provocación de la conducta de individuos y de grupos que es la antítesis clara de la función solamente protectora o solamente represiva".

Aparece la función de alentamiento, por el contrario de la desalentamiento del viejo Estado liberal, donde el Estado social "se vale cada vez más a menudo del procedimiento de incentivación o del premio, es decir, del procedimiento de la sanción positiva", el cual ofrece ventajas significativas para el destinatario de la norma, habida cuenta que le puede proporcionar beneficios si la observa, pero su inobservancia "no tiene ninguna consecuencia jurídica", característica de una función promocional e innovadora (ídem, pp. 269 y 274).

Es decir, a partir de allí se abre camino una "visión sociológica del fenómeno de la sanción", lo que importa cambios significativos en la adopción de nuevas técnicas jurídicas de regulación de la conducta social, habida cuenta de que nos encontramos ahora frente a "una visión que presenta a la sanción no solo como respuesta a las conductas no queridas sino también a las conductas queridas por el Estado" (LARA Chogoyán, op. cit., p. 553).

El Estado liberal, cuyo paradigma de lo normativo era la prohibición y por supuesto la sanción negativa, cuya base material era el desalentamiento, es dejado atrás y cada vez más se suma a lo anterior, por virtud de las transformaciones que impone el Estado social, los mandatos positivos y, por supuesto, las sanciones positivas, cuya base material es el alentamiento o incentivo. 
La sanción jurídica, especialmente la que tiene como esencia una pena o retribución, sufre un giro hacia la preventiva, en tanto ahora en el Estado Social y Democrático de Derecho se trata también de incidir en la vida social con la "motivación de ciertos comportamientos mediante el establecimiento de sanciones positivas (premio) y otro tipo de medidas" (LARA CHOGOYÁN, op. cit., p. 553).

En este nuevo modelo jurídico el "término sanción se usa en sentido amplio para incluir en él no solo las consecuencias desagradables de la inobservancia de las normas, sino también las consecuencias agradables de la observancia" (BoBBIO, op. cit., pp. 372, 375 y 376).

La técnica del alentamiento que informa las nuevas instituciones "tiende no solo a tutelar, sino también a provocar el ejercicio de actos conforme", nueva forma de realización del control social, influyendo psíquicamente en el agente destinatario de la norma, de quien "se quiere un determinado comportamiento". El bien del premio, así, "puede consistir tanto en la atribución de una ventaja como en la privación de una desventaja" (ídem, pp. 380 y ss.).

En fin, se trata de construir la norma de tal manera que para impedir la acción no querida su contenido esencial estriba en referenciar la conducta a partir de "hacerla imposible, hacerla difícil o hacerla desventajosa". Por el contrario, en un ámbito promocional del Derecho estatal de lo que se trata es de promover conductas, por ello el contenido esencial de la norma consistirá en tratar -la conducta- de "hacerla necesaria, factible y ventajosa". Las primeras persiguen fines a través del impedimento de la "realización de los comportamientos socialmente indeseados", las promocionales persiguen como fin provocar "la realización de comportamientos socialmente deseados” (LARA ChOGOYÁN, op. cit., pp. 561 y 562).

En tal marco ideológico, con fuertes raíces en la filosofía analítica a través de la cual se ha develado las nuevas técnicas jurídicas que advienen con la noción de Estado Social, aparece la idea de norma de hacer o de mandato y la sanción estímulo o positiva, lo cual emerge bajo el paradigma de una "definición funcional de la sanción"23.

Esto es, allí se refleja, según Bоввіо, "el paso de un control positivo, que se preocupa más de desfavorecer las acciones nocivas que de favorecer las acciones ventajosas, a un control activo que se preocupa de favorecer acciones ventajosas más que desfavorecer las acciones nocivas". Por ello, "el momento inicial de una medida de desalentamiento es una amenaza; de una medida de alentamiento una promesa" 24.

23 Cfr. LaRa ChOGOYÁn (op. cit., pp. 558 y 559).

24 Cfr. LaRa Chogoyán (op. cit., pp. 563 y 564). 
Ese alentamiento o promesa impacta la información que se suministre sobre personas desaparecidas, medidas inmediatas humanitarias de búsqueda, ubicación, identificación y entrega digna de restos de personas dadas por desaparecidas en el contexto y con ocasión del conflicto, en los programas de limpieza y descontaminación de los territorios de minas antipersona (MAP), artefactos explosivos improvisados (AEI) y municiones sin explotar (MUSE), o restos de explosivos de guerra (REG), repercutiendo en efectos benéficos individuales y sociales para la población en general, todo lo cual deberá tenerse en cuenta al momento de imponer las sanciones, traduciéndose en los tratamientos benignos que contempla el acuerdo y los modelos diferenciados de sanción jurídica.

Es decir, no basta con la desmovilización que ya de por sí comporta importantes beneficios en la sociedad globalmente considerada. Se requiere estimular a los infractores a revelar la plena verdad de lo ocurrido con las víctimas, lo que evita intercambio de impunidades, puesto que se requiere que los perpetradores de violaciones a los Derechos Humanos y al Derecho Internacional Humanitario "hagan el correspondiente reconocimiento" (punto 5.1.).

Un sistema de justicia articulado y complementario, con pretensiones de integralidad, como lo anota el punto 5.1., reclama estimular comportamientos positivos de los infractores con miras a la obtención de la verdad, justicia, reparación y no repetición, lo que puede ser compensado como un sistema punitivo diferencial y otorgante de beneficios, de conformidad con el comportamiento procesal asumido. De allí que se diga que el funcionamiento del componente de justicia es inescindible y se aplicará de manera simultánea e integral (5.1.2. desagregado I-Principios básicos-, numeral 15).

Esto es, "para acceder al tratamiento especial previsto en el componente de Justicia del SIVJRNR es necesario aportar verdad plena, reparar a las víctimas y garantizar la no repetición. Aportar la verdad pelma significa relatar, cuando se disponga de los elementos para ello, de manera exhaustiva y detallada las conductas cometidas y las circunstancias de su comisión, así como las informaciones necesarias y suficientes para atribuir responsabilidades, para así garantizar la satisfacción de los derechos de las víctimas a la reparación y a la no repetición. Se entiende por tratamiento especial las sanciones propias y alternativas previstas en el numeral 60" en un marco de respeto por el debido proceso y el derecho de defensa, en aras de cumplir con el principio según el cual, "todas las decisiones judiciales sobre responsabilidades y sanciones de personas serán debidamente motivadas y fundamentadas en pruebas confiables y admisibles ante tribunales de justicia" (punto 5.1.2. desagregado I Principios básicos-, numerales 13 y 14).

Pero es obvio que, se demanda en los párrafos finales del punto 5.1., los mecanismos utilizados "no pueden entenderse de manera aislada" y sobre todo "estarán interconectados a través de relaciones de condicionalidad y de incentivos para acceder y 
mantener cualquier tratamiento especial de justicia, siempre fundados en el reconocimiento de verdad y responsabilidades", lo cual requiere de verificación judicial.

Visión estructural y visión funcional del Derecho se identifican en el acuerdo, al señalarse, en la última parte del punto 5.1., que "ningún mecanismo del Sistema primará sobre el otro. Cada mecanismo deberá cumplir su función principal de la manera más ágil posible y sin duplicar aquellas de los otros mecanismos, para lo cual se establecerán los protocolos de colaboración necesarios".

Sin duda alguna, es el mejor mecanismo para lograr, como se pretende a través de la llamada "integralidad del sistema", el "esclarecimiento de la verdad del conflicto y la construcción de la memoria histórica" (punto 5.1.).

También, en el mismo punto, se revela la superación de las sanciones negativas, puesto que "el Sistema Integral hace especial énfasis en medidas restaurativas y reparadoras, y pretende alcanzar justicia no solo con sanciones retributivas". Como compensación o ventaja para los infractores, "el Sistema debe también garantizar a la vez la seguridad jurídica de quienes se acojan a las medidas de justicia, como elemento esencial de la transición a la paz" (puntos 5.1. y 5.1.2. I, numeral 2) y, por supuesto, tratándose de un proceso político, no inhabilitará a sus sujetos pasivos que resulten condenados en el ejercicio de derechos y participación política (punto 5.1.2. desagregado II -Contenidos, alcances y límites-, numeral 36).

Como se dijo, el comportamiento procesal del procesado es determinante en el curso del proceso, toda vez que "el grado de contribución voluntaria de cada persona o colectivo a la verdad estará en relación con el tratamiento a recibir en el componente de justicia", lo cual inclusive aplica para los amnistiables e indultables, toda vez que ello "no exime del deber de contribuir, individual o colectivamente, al esclarecimiento de la verdad conforme a lo establecido en este documento", como tampoco al deber de reparar a las víctimas (punto 5.1.2. desagregado II-Contenidos, alcances y límites-, numerales 27,28 y 43).

El comportamiento procesal determina competencias y procedimientos: "La persona que haya guardado silencio, una vez sea ubicada, en caso de aceptar las responsabilidades será acreedora de las sanciones ya impuestas siempre que cumpla las condiciones del Sistema. En caso de no aceptar responsabilidades o mantener silencio, será remitida a la Unidad de Investigación y Acusación”, lo que implica diferenciación por virtud de colaboración (punto 5.1.2. desagregado III -Procedimiento, órganos y sanciones-, numerales 47 y 48 literal (q).

También, el hecho de acogerse al sistema y cumplir con sus directrices enerva la extradición relacionada con conductas de las cuales conoció el sistema (punto 5.1.2. desagregado III -Procedimiento, órganos y sanciones-, numeral 72). 
Otro mecanismo importantísimo vinculado con razones de oportunidad tiene que ver con la selección, descongestión, acumulación y priorización de casos y trámites procesales (punto 5.1.2. desagregado III -Procedimiento, órganos y sanciones-, numerales 48 literal (s), 50 literales (c) y (g) y 51 literal (d).

En fin, resulta determinante el concepto de "casos más representativos" para la toma de medidas como las antes anunciadas (punto 5.1.2. desagregado III -Procedimiento, órganos y sanciones-, numeral 50 literal (c).

Cuando no haya reconocimiento de verdad y responsabilidad, operará un sistema semejante al de la justicia tradicional, fundado en la idea de juicio contradictorio. Esto es, se "valorará si la persona acusada reúne los requisitos establecidos en el sistema para acceder al tratamiento especial previsto, al no haber intentado sustraerse a la competencia del mismo. En caso contrario, el acusado no tendrá la opción de reconocer verdad y responsabilidad", casos en los cuales la pena a imponer será la ordinaria "para los que no reconozcan verdad ni asuman responsabilidades, si resultaren condenados" (punto 5.1.2. desagregado III -Procedimiento, órganos y sanciones-, numeral 52 y 54 ).

Comienza a perfilarse en el acuerdo sobre justicia aquella distinción magistralmente efectuada por Bоввіо, según la cual, conceptualmente, debe advertirse sobre la consagración en los ordenamientos jurídicos de técnicas sancionatorias que conllevan a un intercambio entre sujetos que dan la orden y sujetos que resultaren sancionados por desobedecerla, así: i) Intercambio negativo donde, ante el mal causado por el destinatario de la norma se reacciona con otro mal, encarnado en la sanción negativa (mal por mal); y, ii) Intercambio positivo donde lo realizado por el destinatario de la norma se considera un bien y la respuesta sancionatoria del Estado encarna la realización de otro bien (bien por bien) (LARA CHOGOYÁN, op. cit., p. 560).

En palabras de Bоввіо, la "sanción negativa y la sanción positiva dan origen a dos distintas relaciones en las que se invierte la figura del sujeto activo (titular del derecho) y la del sujeto pasivo (titular del deber): en el primer caso, la relación derecho-deber va del sancionante al sancionado, mientras que en el segundo, la misma relación va del sancionado al sancionante" (ídem, pp. 564 y 565).

Desde esta perspectiva, obviamente, podemos encontrar el pensamiento subyacente en la justicia transicional: la idea central sobre la cual se desarrollaron estas consideraciones tiene como presupuesto el que "el Derecho Penal de la Justicia Tradicional es un derecho penal mínimo; el de la justicia transicional es un mínimo de ese derecho penal".

Si así no fuera, no se entendería la expresión "justicia transicional”, a la cual se llega por virtud de un acuerdo pacífico realizado entre las partes que se traban en un conflicto. 


\section{JUSTICIA SILOGÍSTICO-FORMAL Y JUSTICIA EN EQUIDAD: HACIA UN CONCEPTO DE JUSTICIA CONSTITUCIONAL- UNIVERSAL CENTRADA EN DERECHOS HUMANOS}

El sistema institucional de justicia se encuentra altamente formalizado. Ello no depende, en principio, de las personas que la representan, sino del "estado del arte" de su comprensión ${ }^{25}$.

En la formación del abogado, especialmente a través de la cátedra de "Introducción al estudio del Derecho", se nos enseña desde el primer año o semestre, lo cual marca el pensamiento jurídico de los aprendices, que la materia jurídica está dada por un supuesto de hecho y un supuesto de derecho, identificables en la ley a través de las llamadas parte preceptiva y parte sancionatoria de la norma, siendo la tarea del juez la de simple subsumidor de hechos en normas, forma silogística de la justicia que se identifica en la premisa mayor, premisa menor y síntesis, lo cual evoca y materializa la idea y visión del "juez boca de la ley".

Desde ARISTÓTELES, se decía que la aplicación irrestricta de la letra de la ley no observa la imperiosa necesidad de hacer justicia, razón por la cual debe abrirse camino a la equidad, que es la mejor forma de hacer justicia caso por caso.

Los mecanismos que integran la justicia no pueden ser conceptualizados como cuadriculados, a imagen y semejanza de camisas de fuerza, pues el juez se ocupa de lo más esencialmente humano. El juez moderno, sin adscribirse funciones ejecutivas y legislativas, debe ser el protagonista de la justicia, no es irrestrictamente necesario que sea la "boca de la ley", tampoco un creador libre del Derecho, pero no debe operar solo con fundamento en la abstracción y subsunción, debe "salir del círculo mágico de sus fórmulas abstractas, del cerrado horizonte de las normas, y afrontar directamente el problema de los contenidos materiales de la justicia" 26 .

Por ello, ante las evidentes injusticias de la lógica formal silogística de la tradición jurídica, debe actuar de conformidad con la Constitución Política y los Tratados Internacionales sobre Derechos Humanos ${ }^{27}$.

Esto implica el reconocimiento del Bloque de Constitucionalidad, del carácter normativo de la Carta Política, del efecto general e inmediato de sus normas y del efecto irradiante que los principios, valores y derechos constitucionales fundamentales ejercen sobre la legislación infraconstitucional, lo cual debe ser atendido y sin excusas por las autoridades de la República, especialmente cuando son jueces.

25 Para el efecto, muy especialmente, BACHOF (1985).

26 Así Barcellona (op. cit., pp. 43 y ss.).

27 Para el efecto, Gómez Pavajeau (2015 y 2012). 


\section{JUSTICIA EXPIATORIA-RETRIBUTIVA Y JUSTICIA PREVENTIVA- REPARADORA-ASEGURATIVA: HACIA UN CONCEPTO DE JUSTICIA QUE NO OLVIDE EL PASADO PERO QUE SE CENTRE EN EL FUTURO}

La filosofía del sistema sancionatorio descansa en la idea de que el "Sistema Integral hace especial énfasis en medidas restaurativas y reparadoras, y pretende alcanzar justicia no solo con sanciones retributivas" (punto 5.1.).

Todas las normas mencionadas a continuación pertenecen al desagregado III -procedimiento, órganos y sanciones del componente de justicia del SIVJRNR-, de tal manera que los numerales citados pertenecen a dicho aparte, lo que demuestra una organización y ordenación sistemática de los conceptos.

Se descarta una visión de la pena fundada en la expiación y/o en la retribución, que solo mira al pasado, bien para servir de instrumento de salvación de almas o de compensar el daño antijurídico con otro daño jurídico -la pena-, propias de concepciones metafísicas alejadas de la realidad social.

De manera que, en forma categórica, se dispone que la finalidad esencial de las sanciones -acento sobre el concepto de pena- es "satisfacer los derechos de las víctimas y consolidar la paz. Deberán tener la mayor función restaurativa y reparadora del daño causado, siempre en relación con el grado de reconocimiento de la verdad y responsabilidad que se haga ante el componente de Justicia del SIVJRNJ mediante declaraciones individuales y colectivas".

Significa lo anterior, de manera clara y categórica, que las sanciones están orientadas a finalidades preventivas, que buscan fundamentalmente evitar hacia el futuro la comisión de los hechos investigados, mirando solo al pasado en la medida en que construya futuro, a través de los conceptos de restauración y reparación y muy especialmente por lo relacionado con el elemento reconocimiento de verdad y responsabilidad, todo lo cual se engarza sistemáticamente con la no repetición.

Se habla de sanciones propias del sistema y ordinarias, empero, es asunto no de sustancia sino de grado, toda vez que también estas últimas se encuentran permeadas por las finalidades del sistema de Justicia Especial para la Paz (JEP).

La diferencia, en realidad, es en cuanto al instrumento procesal utilizado para llegar a la sanción, puesto que en las propias o alternativas su fundamento es el "reconocimiento de verdad y responsabilidad", mientras que en las ordinarias es el "juicio contradictorio" (numeral 60 y Listado de sanciones).

De todos modos, es claro que las propias del sistema se inclinan más por las funciones preventivas, en grado superlativo, mientras que las ordinarias tienen un componente 
retributivo que, en nuestro sentir, opera más como elemento fundamentador y limitante de la culpabilidad y de la pena.

Las sanciones propias del sistema son sanciones alternativas graduables, que dependen fundamentalmente del grado de reconocimiento de la verdad y responsabilidad y del momento procesal -ante las salas o ante el Tribunal- en que se hacen, pues mientras sean mayores los aspectos que muestran sinceridad con el sistema, la sanción aparece en forma más benigna.

Cuando el grado de compromiso con la justicia transicional sea mayor, lo que se aplica para "infracciones graves", sin dejar de lado las funciones restauradoras y reparadoras, la sanción consistirá en una restricción efectiva de la libertad sin que se entienda detención intramural, con restricciones de la libertad y derechos como la "libertad de residencia y movimiento", con garantía de no repetición. Todo lo cual debe ir acompañado de las necesarias medidas de control para verificar su cumplimiento, con los debidos mecanismos idóneos de "monitoreo y supervisión" (numerales 60,62 y 63).

La verdad y reconocimiento, para que sean validados acorde con las finalidades del sistema de JEP, deberán ser "exhaustivos, completos y detallados", sin que ello sea impedimento para justificar deficiencias en casos excepcionales. En fin, la pena alternativa demanda comportamiento excelente y orientado en su ejecución a la no repetición.

Cuando se trate de "infracciones muy graves", se hará énfasis en el carácter retributivo de la pena; empero, se mantendrán sus límites dentro de los tiempos ya señalados.

Incluso, por debajo de la restricción temporal anotada, para quienes no hayan tenido una "participación determinante en las conductas más graves y representativas", la pena oscilará entre dos y cinco años.

Las sanciones ordinarias se corresponden con las consagradas por el Derecho Penal Común y tendrán lugar para quienes no aporten "reconocimiento de verdad y responsabilidad", y regirá una idea de función acorde con las allí consignadas. No obstante, muy a pesar de que se denominan "ordinarias", el toque y la naturaleza de la transicionalidad no le son ajenos, puesto que oscilarán entre quince y veinte años, con posibilidades de redención "siempre y cuando el condenado se comprometa a contribuir con su resocialización a través del trabajo, capacitación o estudio durante el tiempo en que permanezca privado de la libertad". También tendrán derecho a "subrogados penales y beneficios adicionales" por su buen comportamiento.

Pareciera que existe una contradicción con lo dicho anteriormente cuando, en el desarrollo de los principios que gobiernan las sanciones, se afirma que "las denominadas sanciones alternativas y ordinarias, sí incluirán privaciones efectivas de 
la libertad como cárcel o prisión y/o cualquier medida de aseguramiento", lo cual debe entenderse, muy a pesar que de todos estos principios se necesitan desarrollos legislativos más concretos y específicos, cuando los principios han señalado que en tales modalidades se cumple una función "esencialmente retributiva".

Para evitar discriminaciones negativas, todas las anteriores se extienden a los restantes partícipes en el conflicto diferentes a los rebeldes, con sus propias especificidades.

Según el "Listado de sanciones", su gradualidad dependerá de factores vinculados con la ejecución de los hechos delictivos - gravedad de la conducta sancionada y nivel de participación y responsabilidad-y con los factores que contribuyan de manera esencial con la consecución de la paz, como sucede con "el grado de verdad otorgado a la persona" y "los compromisos en materia de reparación a las víctimas y garantías de no repetición”.

Las sanciones ya comentadas se acompañarán de actividades, trabajos y obras llevadas a cabo en forma personal o colectiva por el grupo desmovilizado. Son de importancia cardinal por sus efectos restauradores y reparadores en términos globales, como la limpieza de materiales de guerra, sustitución y erradicación de cultivos ilícitos, construcción de infraestructuras, con los debidos controles y monitoreo de supervisión.

Se podrán realizar en zonas rurales y urbanas, lo que demanda cercanía de vivienda de los comprometidos y participación de las víctimas.

\section{JUSTICIA CON UNIDAD DE JURISDICCIONES Y JUSTICIA ESPECIAL: HACIA UN CONCEPTO DE JUSTICIA TRANSICIONAL INTEGRATIVA}

El sistema de Justicia Especial para la Paz “prevalecerá sobre las actuaciones penales, disciplinarias o administrativas por conductas cometidas con ocasión, por causa y en relación directa o indirecta con el conflicto armado, al absorber la competencia exclusiva sobre dichas conductas", tratamiento diferente según el origen de los actores, pero "equilibrado y equitativo" (punto 5.1.2. desagregado II - Contenidos, alcances y límites-, numerales 33, 34 y 42 y en el respectivo desagregado III -Procedimiento, órganos y sanciones-, numerales 50 literal (f) y 52). También así se puede verificar en el punto 5.1.2. desagregado III -Procedimiento, órganos y sanciones-, numeral 63.

Por tal virtud, lo decidido hará "tránsito a cosa juzgada cuando estén en firme -las decisiones- y se garantizará su inmutabilidad". "Cualquier decisión adoptada por un órgano jurisdiccional u otra autoridad que pretenda dejar sin efecto la amnistía, el indulto u otra medida adoptada por el sistema, tendrá que ser sometida al Tribunal para la Paz, para que este verifique" el cumplimiento del acuerdo sobre Justicia y 
Paz (punto 5.1.2. desagregado III -Procedimiento, órganos y sanciones-, numerales 56 y 57$)$.

El concepto de jurisdicción se utiliza en sentido amplio, para efectos judiciales y administrativos. En los primeros, se menciona a la Comisión de Acusaciones de la Cámara de Representantes o el órgano que la reemplace, a la justicia penal militar, a la Jurisdicción de Justicia y Paz consagrada en la Ley 975 de 2005 y a "cualquier jurisdicción que opere en Colombia"; en los segundos, a la Procuraduría General de la Nación y la Contraloría General de la República (punto 5.1.2. desagregado III -Procedimiento, órganos y sanciones-, numeral 48 literal (b).

Se excluyen los destinatarios sometidos a la Jurisdicción Indígena por virtud de lo dispuesto en el artículo 246 de la Carta Política y al fuero presidencial constitucional (punto 5.1.2. desagregado III -Procedimiento, órganos y sanciones-, numerales 73 y 32$)$.

Los límites temporales son claros, toda vez que el sistema no conocerá conductas cometidas con posterioridad a su entrada en vigor (punto 5.1.2. desagregado I -Principios básicos-, numeral 9).

También esta idea orientadora se manifiesta en la posibilidad de admitir magistrados extranjeros, y dadas las exigencias de especialidad de todos los que conformen la JEP, de tener una alta calificación profesional, incluyendo expertos en diferentes ramas del derecho, con énfasis en Derecho Internacional Humanitario, Derechos Humanos y resolución de conflictos

\section{JUSTICIA CON FUNCIONES DIFERENCIADAS EN CABEZA DE DIFERENTES ÓRGANOS O JUSTICIA ÚNICA EN CABEZA DE UN MISMO ÓRGANO PERO CON FUNCIONES DIFERENCIADAS: HACIA UN CONCEPTO INTEGRADOR DE JUSTICIA}

La Justicia Especial para la Paz aborda sus competencias a partir de un concepto de justicia única, sin jurisdicciones diferenciadas, distinguiendo básicamente en dos componentes: 1) procedimiento en caso de reconocimiento de verdad y reconocimiento de responsabilidad, por medios individuales o colectivos, y 2) procedimiento en caso de ausencia de reconocimiento de verdad y responsabilidad, con la finalidad especial de "administrar justicia e investigar, esclarecer, perseguir y sancionar las graves violaciones a los derechos humanos y las graves infracciones al Derecho Internacional Humanitario". A su vez, al interior del sistema, órganos diferentes se ocuparán de temas como: 1) reconocimiento de verdad, de responsabilidad y determinación de los hechos y conductas; 2) Tribunal para la Paz, el cual se constituirá en el "órgano de cierre de la jurisdicción especial para la paz"; 3) Sala de amnistía o indulto; 4) Sala de definición de situaciones jurídicas y 5) Unidad de Investigación 
y Acusación (puntos 5.1 y 5.1.2. desagregado III -Procedimiento, órganos y sanciones-, numerales 45,46 y 47 ).

Tribunal, salas y demás mecanismos de distribución de funciones por especialidad, como las que tienen que ver con aspectos como indultos y amnistías, medidas de aseguramiento, reconocimiento de verdad y responsabilidad, juicios contradictorios en primera instancia, aseguramiento jurídico de los acuerdos e imposición de sanciones, se entienden integrados a una misma jurisdicción, que tiene como cabeza unificadora el Tribunal de JEP.

La JEP pretende, como se ha visto, concentrar la problemática del conflicto en un solo órgano competente, con diferentes funciones especializadas, pero definitivamente especial respecto de las jurisdicciones tradicionales reconocidas en el ordenamiento jurídico permanente.

De allí que, como se vio, tiene el carácter de órgano de cierre, contribuyendo a que los propósitos, finalidades y hermenéutica de la paz no se difuminen en diferentes instancias sin un techo común, donde se disperse la jurisprudencia y se abstraigan los criterios especiales de transicionalidad.

\section{JUSTICIA COMO TRIUNFO DE LA FUERZA O COMO CONCESIÓN ESCANDALOSA DE BENEFICIOS: HACIA UN CONCEPTO DE JUSTICIA POLÍTICO-CONSTITUCIONAL}

Un principio del sistema de la "Jurisdicción Especial para la Paz" señala, de manera terminante, con base en criterios esbozados en un voto concurrente a la sentencia del 25 de octubre de 2012, Corte Interamericana de Derechos Humanos, Caso Masacre de El Mozote vs. El Salvador, que "la paz como producto de una negociación se ofrece como una alternativa moral y políticamente superior a la paz como producto del aniquilamiento del contrario" (puntos 5.1. y 5.1.2. desagregado i -Principios básicos-, numeral 1), verdadera orientación contra aberraciones contemporáneas como el llamado "Derecho Penal del Enemigo".

Incluso, no deja de necesitar recordación lo sucedido con Alemania después de la Primera Guerra Mundial con la firma del Tratado de Versalles, a través del cual se impusieron obligaciones ignominiosas y humillantes que sirvieron de caldo de cultivo para el crecimiento metastásico del nacionalsocialismo alemán y su carácter de causa primera de la Segunda Guerra Mundial.

Dentro de lo complejo de un proceso de paz, donde fuerzas armadas imponen lo físico sobre lo racional, surgen medidas razonables que implican cierto equilibrio entre los beneficios globales logrados y los personales de los infractores, sin llegar a la impunidad y sobre todo manteniendo, como se vio, los fines de verdad, reparación y no repetición, muy especialmente cuando se trata de "las graves infracciones 
del DIH y graves violaciones de los derechos humanos" (punto 5.1.2. desagregado II -Contenidos, alcances y límites-, numeral 21).

Es así como se determina que para rebeldes que hayan cometido delitos políticos y conexos "a la finalización de hostilidades, de acuerdo al DIH, el Estado colombiano puede otorgar la amnistía más amplia posible", empero, "hay delitos que no son amnistiables ni indultables de conformidad con los numerales 40 y 41 de este documento. No se permite amnistiar los crímenes de lesa humanidad, ni otros crímenes definidos en el Estatuto de Roma", aquellos referidos a genocidio, toma de rehenes u otra privación grave de la libertad, tortura, ejecuciones extrajudiciales, desaparición forzada, acceso carnal violento y otras formas de violencia sexual, sustracción de menores, desplazamiento forzado, reclutamiento de menores y delitos comunes que carezcan de relación con la rebelión, límites racionales y razonables, muy a pesar de las críticas sin fundamento en torno al punto (punto 5.1.2. desagregado II -Contenidos, alcances y límites-, numerales $23,25,37,38,39,40$ y 41).

Por ello, tales delitos deben ser objeto de la competencia del sistema de Justicia Especial para la Paz, en el cual se "establecerán sanciones a los responsables en aquellos casos en los que se determine que no los alcanza la amnistía o el indulto" (punto 5.1.2. desagregado II -Contenidos, alcances y límites-, numerales 30 y 31).

No existen vencedores ni vencidos, el sistema de justicia cubre a todo aquel que haya participado, directa o indirectamente, en el conflicto, incluidas las personas que colaboraron con grupos paramilitares sin mediar coacción bajo parámetros de "participación determinante o habitual”, como también "se aplicará respecto de los agentes del Estado que hubieren cometido delitos relacionados con el conflicto armado y con ocasión de este, aplicación que se hará de forma diferenciada, otorgando un tratamiento equitativo, equilibrado, simultáneo y simétrico", con lo cual se busca no discriminar negativamente a todos los participantes en el conflicto (punto 5.1.2. desagregado II -Contenidos, alcances y límites-, numeral 32).

Incluso se consagra que, para evitar injusticias por desvío de poder, "la protesta pacífica, la defensa de los derechos humanos, y el liderazgo de grupos de la sociedad civil, no pueden ser por sí mismos tipificados penalmente, ni penados" (punto 5.1.2. desagregado II -Contenidos, alcances y límites-, numeral 35).

Se prevén, con muy buen criterio, niveles de responsabilidad diferenciables como la comisión por omisión, implementándose reglas dogmáticas para su aplicación (punto 5.1.2. desagregado II -Contenidos, alcances y límites-, numeral 44 y 59).

En los juicios contradictorios, si terminan con sentencia condenatoria, las sanciones "serán de mayor severidad que las impuestas a quienes reconocieron verdad y responsabilidad”, toda vez que aquí se aplican las sanciones ordinarias con algunas 
variables, sin que se desconozca el acento de la justicia transicional (punto 5.1.2. desagregado III -Procedimiento, órganos y sanciones-, numeral 54 literal (c).

\section{JUSTICIA PARA PODEROSOS O JUSTICIA PARA DÉBILES: HACIA UN CONCEPTO DE JUSTICIA SIN DISCRIMINACIONES NEGATIVAS}

Como se puede ver, según todo lo anotado, no se trata ni de una justicia que premie a los poderosos y atropelle a los débiles, pero tampoco lo contrario. Tiene suficientes mecanismos de evaluación para introducir criterios de justicia material y equidad, con cabida fortificante de la perspectiva de género, en todo caso facilitando la discriminación positiva y marginando la discriminación negativa.

\section{JUSTICIA PARAMETRIZADA O JUSTICIA INDIVIDUALIZADA: HACIA UN CONCEPTO DE JUSTICIA COLECTIVA-INDIVIDUAL}

No existen raseros parametrizados para evaluar las conductas. Por el momento, y teniendo en cuenta que todavía hacen falta los desarrollos puntuales y específicos de los principios señalados, de todos modos se percibe al rompe que se consagraron suficientes criterios judiciales, no judiciales, sustanciales, probatorios, procesales, individuales y colectivos, enmarcados en lo político, social, económico y jurídico para que el esfuerzo de paz sea compensado con un futuro mejor para Colombia.

En fin, la esencia y sustancia de este decálogo incidirán en el futuro de la enseñanza del Derecho, despercudiéndose de lo formal y adjetivo, de lo absoluto, dando cabida a lo relativo y sobre todo pábulo para el tránsito de la función del juez como "juez boca de la ley", a la de "cerebro que construye la regla jurídica aplicable al caso controvertido en búsqueda de la justicia material y social" (GÓMEZ PAVAJEAU, 2005, pp. 31 y ss.).

\section{Excursus: la paz como finalidad y fundamento de la justicia transicional y los acuerdos de La Habana como sus instrumentos de consecución}

Un examen sistemático del Derecho Internacional de los Derechos Humanos (en adelante DIDH) y del Derecho Internacional Humanitario (en adelante DIH) es más que suficiente para enarbolar la bandera de la paz como leitmotiv de los Acuerdos de La Habana (ambos con firme anclaje en los artículos 93 y 214 numeral 2 de la Carta Política).

En efecto, la Carta de las Naciones Unidas pone su acento, sin demeritar la dignidad humana, los derechos que de ella emanan y la armonía entre los pueblos, en el supravalor de la paz (Preámbulo y numeral 1 del artículo 1), estableciendo que cuando existan controversias y conflictos entre los pueblos se "arreglarán" por la vía "pacífica" (numeral 3 del artículo 2). 
Si bien lo allí dispuesto va referido a los conflictos y controversias internacionales, los mandatos no son exclusivos y excluyentes y aplican para los de carácter interno, pues donde se exige lo más se exige lo poco, tal como posteriormente se observará respecto de lo que disponen los Convenios de Ginebra.

Señala la Declaración Universal de Derechos Humanos (en adelante DUDH) en su Preámbulo que "la libertad, la justicia y la paz en el mundo tienen por base el reconocimiento de la dignidad intrínseca" de la familia humana. Precisamente, cuando tales valores de humanidad se desconocen, así como también los derechos humanos que se protegen en dicho instrumento, se originan "actos de barbarie ultrajantes para la conciencia de la humanidad", lacerando la aspiración del "advenimiento de un mundo" en que los seres humanos vivan liberados del temor y la miseria, destacada como "la aspiración más elevada del hombre". La dignidad y la igualdad en todos los órdenes, así como "el respeto universal y efectivo por los derechos", implican la promoción del "progreso social", cuya materialización demanda "medidas progresivas de carácter nacional e internacional".

Con lo anterior se busca asegurar, según el Preámbulo, que "el hombre no se vea compelido al supremo recurso de la rebelión contra la tiranía y la opresión”, principio que, interpretado contrario sensu, indica que cuando se ha llegado a tal situación deben tomarse todas las medidas necesarias que consagran el Derecho Internacional de los Derechos Humanos y el Derecho Internacional Humanitario para superar el statu quo de injusticia y guerra.

Precisamente, como todo hombre nace libre e igual, dotado de razón y conciencia, con el correlativo deber de solidaridad de "comportarse fraternalmente" (artículo 1 CUDH), debe procurar por todos los medios políticos, jurídicos, sociales y económicos la obtención de la justicia y la paz, para asegurar así la vida, la libertad y la seguridad de su persona (artículo 3) y la seguridad social (artículo 22 ibídem).

Se debe propender a la comprensión y tolerancia entre los grupos humanos y las personas en general como presupuestos de la paz (artículo 26 numeral 2 DUDH), así como también por los "deberes de respeto a la comunidad" (artículo 29), con el fin de lograr socialmente "un nivel de vida adecuado" y "el bienestar" (artículo 25), compatible con la existencia de "un orden social internacional" que haga efectivos los derechos y libertades proclamados en la Declaración (artículo 28 ibídem).

La Declaración Americana de los Derechos y Deberes del Hombre (en adelante DADDH) en su Preámbulo enfatiza en derechos pero especialmente en deberes de las personas, refrendando el de fraternidad, imponiéndola como guía de conducción del comportamiento social, puesto que el "cumplimiento del deber de cada uno es exigencia del derecho de todos. Derechos y deberes se integran correlativamente en toda actividad social y política del hombre", habida cuenta que es "deber del hombre servir al espíritu con todas sus potencias y recursos". 
De allí que, su capítulo segundo, sobre los “Deberes", señala en el artículo Xxix que "toda persona tiene el deber de convivir con las demás, de manera que todas y cada una puedan formar y desenvolver integralmente su personalidad". Por supuesto, tiene que ser así, toda vez que "los derechos de cada hombre están limitados por los derechos de los demás, por la seguridad de todos y por las justas exigencias del bienestar general y del desenvolvimiento democrático" (artículo XXVIII).

El Pacto Internacional de Derechos Económicos, Sociales y Culturales (PIDESC), al igual que el Pacto Internacional de Derechos Civiles y Políticos (en adelante PIDCP), reconocen en sus preámbulos los valores superiores de libertad, justicia y paz, teniendo como base el reconocimiento de la dignidad del ser humano, los derechos inalienables que de allí se desprenden y los "deberes respecto de otros individuos", los cuales deben ser ejercidos en condiciones económicas, sociales, culturales, civiles y políticas "liberado del temor y la miseria" por parte del individuo. Según sus numerales 1 de los artículos 1, allí se encuentra la base sustancial sobre la cual se reconoce la "libre determinación de los pueblos".

Tanto uno como otro pacto, en sus artículos 3, demandan a los Estados Partes garantizar sin distinción alguna el goce de todos y absolutamente todos los derechos en ellos consignados.

El PIDCP, en el numeral 1 de su artículo 4, consagra la posibilidad de que en "situaciones excepcionales", se puedan suspender algunos derechos y libertades garantizados en su cuerpo normativo, eso sí "en la medida estrictamente limitada a las exigencias de la situación", siempre y cuando "no sean incompatibles con las demás obligaciones que les impone el derecho internacional".

En la misma senda camina la Convención Americana sobre Derechos Humanos (en adelante $\mathrm{CADH}$ ), reiterando de manera expresa y explícita lo expuesto por la DUDH y la CADDH, utilizando la expresión "justicia social” como componente más complejo de los antecedentes referenciados, lo que potencia a sus miembros a lograr el objetivo de encontrarse exentos del "temor y la miseria", lo cual refrenda en su artículo 1, en un nivel superior de exigencia y demanda de garantía material, en armonía con deberes correlativos y exigencias del bien común como límites a los derechos y libertades (artículos 30 y $32 \mathrm{CADH})$.

La superación de situaciones excepcionales que afectan masivamente los derechos humanos es asunto de primer orden a solucionar. Si es dable, dentro de condiciones estrictas, suspender derechos para evitar que se consoliden situaciones desfavorables al desarrollo de los mismos, con mayor razón se pueden tomar otras medidas extremas cuando dichas situaciones se han enraizado en la sociedad, como reducir la proporcionalidad entre gravedad de los delitos y sus condignas sanciones -justicia proporcional-, siempre y cuando otros estándares se vean impactados positi- 
vamente, como sucede con la verdad, la reparación y la no repetición, en un marco de justicia preventiva.

Entre las disposiciones que obligatoriamente deben adoptarse a nivel interno de los Estados Partes en el marco del DIDH, se mencionan las legislativas, pero también las "de otros carácter necesarias", nominación abierta y flexible determinable por la "necesidad de consecución del fin" de hacer efectivos los derechos humanos. Los instrumentos son los constitucionales, pero también los convencionales, como expresamente se dice en su redacción (artículo $2 \mathrm{CADH}$ ).

Las medidas de suspensión de garantías por razones excepcionales también se contemplan en la $\mathrm{CADH}$, mencionándose ahora -no en abstracto, el peligro para la vida de la nación- la guerra, el peligro público y las emergencias que amenacen la independencia o seguridad del Estado (artículo 27), con los demás ribetes de exigencias y limitaciones contempladas en el PIDCP en su artículo 4.

Se destaca que, tanto en el artículo 4 del PIDCP como en el 27 de la CADH, la compatibilidad se demanda respecto del "derecho internacional", lo que significa que juegan en su determinación tanto el Derecho Internacional de los Derechos Humanos como el Derecho Internacional Humanitario.

Si la actividad de las FARC en Colombia pone en peligro la vida de la Nación, pues los componentes guerra, peligro público y emergencias que amenazan la independencia o seguridad del Estado son evidentes, llevan más de sesenta años en actividad regular, continua y persistente, tozuda por demás, es necesario tomar medidas para que se cumplan los ideales expuestos por las declaraciones universal y americana sobre derechos y deberes de las personas, así como los desarrollos que de las mismas hacen el PIDESC, PIDCP y CADH.

La paz y la justicia social son los objetivos últimos, los supravalores que determinan el proceso de justicia transicional que actualmente se surte en Colombia, pues pensar lo contrario es tanto como desconocer y andar de espaldas al Derecho Internacional de los Derechos Humanos y el Derecho Internacional Humanitario.

La Declaración sobre el Derecho de los Pueblos a la Paz de $1984^{28}$ refrenda que "el mantenimiento de la paz y la seguridad internacionales" es propósito principal de las Naciones Unidas, lo que expresa la voluntad de todos los pueblos por "eliminar la guerra de la vida de la humanidad".

28 Su valor normativo estriba en lo dispuesto en el literal d) del artículo 29 de la Convención Americana sobre Derechos Humanos. 
Es necesario propiciar "una vida sin guerras", puesto que ello se constituye en "el requisito previo primordial para el bienestar material, el florecimiento y el progreso de los países y la realización total de los derechos y las libertades fundamentales del hombre proclamados por las Naciones Unidas".

Por ello establece, a partir de una fórmula imperativa, que debe garantizarse "que los pueblos vivan en paz [como] deber sagrado de todos los Estados"; consecuencia, en su reconocimiento $n .^{\circ} 1$, establece que "los pueblos de nuestro planeta tienen el derecho sagrado a la paz", y todo Estado debe proteger "el derecho de los pueblos a la paz y fomentar su realización" (Reconocimiento n. ${ }^{\circ} 2$ ).

Si bien en principio pareciera que ello solo tiene alcance internacional, su reconocimiento n. ${ }^{\circ} 4$ establece que también es obligación de todos los Estados y la "adopción de medidas pertinentes [debe ser] en los planos nacional e internacional".

Así también procede a ordenarlo la Declaración sobre el Derecho al Desarrollo de 1986 de las Naciones Unidas, que propende a: a) el desarrollo integral del ser humano; b) el respeto y la observancia de los derechos humanos; c) el progreso y desarrollo económicos de todos los pueblos, y d) la libertad de determinación política de los pueblos.

Entre otras razones, ello tiene como motivo la "eliminación de las violaciones masivas y patentes de los derechos humanos de los pueblos".

Así lo dispone de manera perentoria en sus artículos 1,2 y 3. El artículo 2 establece que todos los seres humanos y los pueblos "deben promover y proteger un orden político, social y económico apropiado para el desarrollo" (numeral 2) y formular políticas "adecuadas con el fin de mejorar constantemente el bienestar de la población entera" (numeral 3).

Para eliminar las violaciones masivas y patentes de los derechos humanos, los Estados, ante amenazas externas e internas, especialmente por la guerra, deben adoptar "medidas enérgicas" (artículo 5) y "el desarme general y completo bajo un control internacional eficaz" (artículo 7), así como llevar a cabo "reformas económicas y sociales adecuadas con objeto de erradicar todas las injusticias sociales" (artículo 8), tanto en el plano nacional como internacional (artículo 10).

Si bien de los otros documentos se infiere que entre las medidas a tomar se encuentran aquellas que incumben a la voluntad popular, el numeral 2 del artículo 8 de esta declaración específicamente señala que se debe "alentar la participación popular en todas las esferas.

La indivisibilidad y la interdependencia de derecho y deberes obliga a realizar interpretaciones que conlleven a la toma de medidas contextuales entendidas dentro del 
conjunto de instrumentos del Derecho Internacional de los Derechos Humanos y del Derecho Internacional Humanitario (así, por ejemplo, el artículo 9 de la Declaración sobre el Derecho al Desarrollo de 1986 de las Naciones Unidas).

Los cuatro convenios de Ginebra: $i$ ) para aliviar la suerte que corren los heridos y los enfermos de las Fuerzas Armadas en campaña; $i$ ) para aliviar la suerte que corren los heridos, los enfermos y los náufragos de las Fuerzas Armadas en el mar; iii) relativo al trato debido a los prisioneros de guerra, y $i v$ ) relativo a la protección debida a las personas civiles en tiempos de guerra, consagran el Derecho Internacional Humanitario, complementados con sus Protocolos Adicionales I y II.

En el Convenio $i$ ) se establecen en múltiples oportunidades los eventos en que se pueden llevar a cabo negociaciones y acuerdos, señalándose en principio la libertad de negociar por las partes (artículo 10) y la viabilidad de realizar la concertación por estas de armisticio, interrupción del fuego y acuerdos locales para disminuir los efectos inhumanos de la guerra (artículo 15), también los anteriores pero ya en paz (artículo 23), "acuerdos con respecto al eventual relevo del personal retenido" (artículo 28), acuerdos especiales sobre retenidos (artículo 31), concertación sobre operaciones de aeronaves sanitarias (artículos 36 y 37) y acuerdos sobre Encuestas ante las violaciones al convenio (artículo 52).

Tales acuerdos son avalados por los otros convenios -ii), iii) y iv)-, pero destácase que el convenio $\mathrm{iii}$ ) contempla acuerdos de repatriación sobre prisioneros enfermos (artículo 109) y sobre Procedimientos de Encuestas (artículo 132).

El convenio iv) agrega otros acuerdos como los relacionados con Potencias Protectoras (artículo 11), acuerdos sanitarios en época de paz (artículo 14), acuerdos para protección de personas protegidas por el DIH (artículo 15), acuerdos sobre evacuación de sujetos ajenos al conflicto (artículo 17), acuerdos sobre desplazamiento de personas, canje y repatriación (artículo 36), acuerdos sobre objetos de los sujetos afectados por el conflicto (artículos 108 y 109), acuerdos sobre liberación, repatriación, regreso al domicilio y hospitalización de prisioneros y personas en debilidad física manifiesta (artículo 132), acuerdos sobre comisiones de búsqueda de internados (artículo 133) y acuerdos para Encuestas sobre violación al convenio (artículo 149).

De manera especial, el artículo 3, común a los cuatro convenios, establece que sus disposiciones se aplican también a un conflicto "que no sea de índole internacional", con todas las posibilidades de realizar "acuerdos especiales" (numeral 2 ibídem) sobre la totalidad de la temática en ellos tratados. Es decir, los descritos en el párrafo anterior son meramente enunciativos o ejemplificativos, pero el sistema utilizado es de numerus apertus, de conformidad con el numeral precisado.

Así también se desprende de su artículo 6 común -para el Convenio iv aparece en el artículo 7-, toda vez que señala que además de los anteriores acuerdos especiales, 
se podrán llevar a cabo otros "sobre cualquier cuestión que les parezca oportuno -a las partes-zanjar particularmente”.

El numeral 1 del artículo 1 del Protocolo Adicional II extiende de manera expresa los Convenios de Ginebra a los eventos de conflictos internos suscitados entre las fuerzas armadas de los Estados y "fuerzas armadas disidentes o grupos armados organizados que, bajo la dirección de un mando responsable, ejerzan sobre una parte de dicho territorio un control tal que les permita realizar operaciones militares sostenidas y concertadas y aplicar el presente Protocolo". El numeral 2 del mismo artículo expresa la no aplicación del Protocolo "a las situaciones de tensiones internas y de disturbios interiores tales como los motines, los actos esporádicos y aislados de violencia y otros actos análogos, que no son conflictos armados".

Importa sin duda al DIH todo lo relacionado con el DIDH, puesto que en los considerandos del Protocolo II se recuerda que "los instrumentos internacionales de los derechos humanos ofrecen a la persona humana una protección fundamental".

Si la paz y la justicia social son supravalores de la humanidad, si los pueblos a través del respaldo popular pueden participar en la toma de decisiones que incumben a su sociedad y al progreso, lo que es expresión entre otras de su libre determinación frente a la comunidad internacional en tanto se respeten los derechos y obligaciones establecidos en el DIH y en el DIDH, para lo cual se puede acudir a instrumentos elaborados por el derecho internacional, que para el efecto los Convenios de Ginebra y sus Protocolos Adicionales establecen como tales los acuerdos especiales o arreglos pacíficos entre las partes para, en caso de conflicto interno, abordar "cualquier cuestión que les parezca oportuno zanjar particularmente", incluso en casos verdaderamente excepcionales, que quienes intervienen están dotados de razón y de conciencia, nada se opone a que se lleguen a acuerdos sobre la forma de procesar en justicia los delitos cometidos durante el conflicto, bajo la modalidad de transitoriedad y transicionalidad, forma "enérgica" de asumir una solución de un problema que tantos y tantos años nos ha lacerado como sociedad.

Someter esos acuerdos al examen de la voluntad popular es la más alta estima por el respeto de la dignidad humana de cada persona que pueda participar en los procesos, de acuerdo con el literal c) del artículo 29 de la Convención Americana sobre Derechos Humanos.

La paz, la convivencia y el orden social justo son valores superiores reconocidos en el Preámbulo de nuestra Carta Política, necesarios de desarrollar dentro de un "marco jurídico, democrático y participativo", a partir de su artículo 1, con fundamento en la dignidad humana, la solidaridad y la prevalencia del interés general, promoviendo las autoridades el progreso y la prosperidad general, asegurando la convivencia pacífica y la vigencia de un orden justo (artículo 2). 
De manera específica, el artículo 22 de la Carta Política establece perentoriamente que "la paz es un derecho y un deber de obligatorio cumplimiento".

Los Acuerdos de Paz de La Habana han sido negociados con el Gobierno Nacional, por tanto, a través de un plebiscito o referendo, o como se quiera llamar el instrumento de refrendación, todos los ciudadanos tienen derecho a terminar de conformarlos y controlarlos en tanto son expresiones del poder político (numeral 2 del artículo 40 de la Carta).

A través de ello los colombianos expresan su solidaridad con sus congéneres, respetan y apoyan a las autoridades legítimamente constituidas, participan en la vida política, cívica y comunitaria, propenden al logro y mantenimiento de la paz y colaboran para el buen funcionamiento de la Administración de Justicia (numerales 2, 3, 5, 6 y 7 del artículo 95 de la Carta Política).

En fin, nada se opone en el DIH y en el DIDH a los acuerdos de paz, por el contrario, los mismos son demandables y exigibles dadas las condiciones del conflicto, por la Carta Política, de tal manera que resultan la expresión más alta una vez sean refrendados, del derecho que todos los ciudadanos tienen de participar en las "decisiones que los afectan" (artículo 2 de la Carta), lo cual no tiene color político ni partidista.

\section{Posdata: los Acuerdos de La Habana y la Corte Penal Internacional}

Quienes se oponen a los Acuerdos de Paz de La Habana sacan a relucir que desconocen el DIH y el DIDH; por tanto, la intervención de la Corte Penal Internacional es inminente en Colombia.

Tales mensajes son exagerados y solo cumplen el papel propagandístico de los opositores al proceso.

En nuestro sentir, y es claro que es uno de los pocos procesos de paz que en el mundo lleva a la justicia y sanciona con medidas restrictivas de la libertad a sus máximos jefes, ello no tiene ocurrencia y si bien se demerita la proporcionalidad propia entre delitos y sanciones desde la perspectiva de la justicia tradicional, no es menos cierto que el balanceo o ponderación debe hacerse en el marco del conflicto y respecto de la idea de justicia transicional, saliendo avantes la verdad, la justicia, la reparación y la no repetición.

De todos modos, cualquier consideración escéptica pasa por el tamiz de las causales de admisibilidad de los casos al conocimiento de la Justicia Penal Internacional, que no los asume automáticamente y por el contrario establece un modelo de ponderación y razonabilidad bastante interesante, que no debe perderse de vista según el artículo 17 del Estatuto de Roma. 
Finalmente, de suceder algo imprevisto, es claro que también el Proceso Penal consignado en el Estatuto de Roma consagra un verdadero principio de oportunidad, acorde con la Justicia Transicional, pues el Fiscal podrá abstenerse de llevar adelante la investigación si aparece fundamento razonable para no adelantarla, entre los cuales se encuentra el que "existan razones sustanciales para creer que, aun teniendo en cuenta la gravedad del crimen y los intereses de las víctimas, una investigación no redundaría en interés de la justicia" (literal c del numeral 1 del artículo 53 del Estatuto de Roma). Igual sucede si, una vez llevada a cabo la investigación por la Fiscalía, no existe fundamento razonable para llevar el caso a la Corte Penal Internacional por los mismos motivos antes expuestos (literal c del numeral 2 ibídem).

Esta última disposición también involucra en la temática las facultades del Consejo de Seguridad de las Naciones Unidas (con referencia al párrafo b del artículo 13 ibídem).

\section{BIBLIOGRAFÍA}

B Асноғ Отто (1985). Jueces y Constitución. Madrid: Civitas.

Barcellona, Pietro; Hart, Dieter y Mückenberger, Ulrich (1993). La formación del jurista. Madrid: Civitas.

Bobbio, Norberto (1990). Contribución a la Teoría del Derecho. Madrid: Editorial Debate.

Calvo García, Manuel (2005). Transformaciones del Estado y del Derecho. Bogotá: Universidad Externado de Colombia.

Corte Constitucional. Sentencia C-004 de 2003.

Corte Constitucional. Sentencia C-199 de 2002.

Corte Constitucional. Sentencia C-651 de 1997.

Corte Constitucional. Sentencia T-058 de 1995.

Corte Constitucional. Sentencia T-058 de 1995.

Corte Constitucional. Sentencia T-058 de 1995.

Corte Constitucional. Sentencia T-058 de 1995.

Corte Constitucional. Sentencia T-339 de 1997. 
Corte Constitucional. Sentencia T-406 de junio 5 de 1992, M.P. Ciro Angarita Barón en Gaceta Constitucional Tomo 2, junio de 1992, p. 199.

Corte Constitucional. Sentencia T-597 de 1992.

Corte Constitucional. Sentencias C-178 de 1995, C-836 de 2001 y T-116 de 2004.

Corte Constitucional. Sentencias C-479 de 1992, C-067 de 2003, C-477 de 2005 y C-544 de 2010

Corte Constitucional. Sentencias C-551 de 2003, C-970 de 2004, C-971 de 2004, C-1040 de 2005, C-588 de 2009, C-141 de 2010, C-303 de 2010, C-288 de 2012, C-579 de 2013, C-577 de 2014, C-150 de 2015 y C-053 de 2016.

Corte Constitucional. Sentencias T- 53 de 1994 y T-084 de 1998.

Corte Constitucional. Sentencias T-02 de 1992 y T-532 de 1992.

FARALli, CARLA (2007). La filosofía del derecho contemporánea. Los temas y desafíos. Bogotá: Universidad Externado de Colombia.

Gómez Pavajeau, Carlos Arturo (2012). "Principios y Normas Rectoras", en Aspectos Liberales y Sociales del Derecho Penal. Bogotá: Ediciones Nueva Jurídica.

Gómez Pavajeau, Carlos Arturo (2016). Crítica disciplinaria. Bogotá: Ediciones Nueva Jurídica.

Gómez Pavajeau, Carlos Arturo (2015). “Justicia sin reglas?: formalidad vs. materialidad", en Justicia Transicional -Obra colectiva-. Bogotá: Defensoría del Pueblo - Dirección Nacional de Defensoría Pública.

Gómez Pavajeau, Carlos Arturo (2005). “Aspectos político-jurídicos que informan al Nuevo Código Penal”, en Estudios de Dogmática en el Nuevo Código Penal, Volumen primero. Bogotá: Giro Editores Ltda.

Gómez Pavajeau, Carlos Arturo (2015). “Interpretación y aplicación de normas internacionales sobre Derechos Humanos en materias penal y disciplinaria" en $L a$ lucha por los derechos en el Derecho disciplinario. Bogotá: Ediciones Nueva Jurídica.

Gómez Pavajeau, Carlos Arturo (2012). Introducción al Derecho Penal Constitucional. Bogotá: Ediciones Nueva Jurídica.

Gómez Pavajeau, Carlos Arturo (2009). El derecho disciplinario judicial. Su autonomía e independencia. Bogotá: Escuela judicial "Rodrigo Lara Bonilla". 
Gómez Pavajeau, Carlos Arturo (2005). Elementos y propuestas para el control contencioso administrativo de la actividad disciplinaria. Bogotá: Ediciones Nueva Jurídica.

LARA CHOGOYÁn, RoBERTO (2005). Sobre la función promocional del Derecho. Disponible en http://www.juridicas .unam.mx/publica/librev/rev/jurid/cont/31/pr/pr34.pdf.

Maldonado Tovar, JuAn CAmilo (2016). “Colombianos, ¿programados para ser indolentes?" en El Espectador, n. 37.214, lunes 13 de junio de 2016.

Montoya Brand, Mario (s.f.). Derecho y política en el pensamiento de Bobbio: una aproximación. Disponible en http://aprendeenlinea.udea.edu.co/revistas/index. php/estudiospoliticos/article/viewFile/1407/1452.

Pérez Lledó, JuAn Antonio (s.f.). Sobre la función promocional del Derecho. Un análisis conceptual. Disponible en http://rua.ua.es/dspace/bitstream/10045/10282/1/ doxa23_26.pdf.

VOLK, KLAUS (2001). "Los principios del proceso penal y la sociedad posmoderna: contradicciones y perspectivas”, en Constitución y Sistema Acusatorio. Bogotá: Universidad Externado de Colombia. 